Karadeniz Uluslararası Bilimsel Dergi

Volume: 49, Spring-2021, p. (226-237)

ISSN: 1308-6200 DOI Number: https://doi.org/10.17498/kdeniz.870548

Research Article

Received: January 29, 2021 | Accepted: March 17, 2021

This article was checked by turnitin.

\title{
REKLAM AJANSLARININ KARŞILAŞTIĞI RENK KAYNAKLI PROBLEMLER VE ÇÖZÜM ÖNERILERİ
}

\section{PROBLEMS RELATED COLOR FACED BY ADVERTISING AGENCIES AND SOLUTION RECOMMENDATIONS}

\section{ПРОБЛЕМЫ РЕКЛАМНЫХ АГЕНСТВ СВЯЗАННЫЕ С ЦВЕТНЫМ ОФОРМЛЕНИЕМ И РЕКОМЕНДАЦИИ ПО ИХ РЕШЕНИЮ}

\author{
Mustafa Batuhan KURT ${ }^{*}$
}

Öz

Basılı reklam iletişim sektörünün en önemli araçlarından biridir. Etkili ve doğru kullanıldığg takdirde, geniş kitlelere ulaşmak ve istenilen bilgileri sağlıklı şekilde aktarmak mümkündür. Reklamların görselleştirilmesi sürecine hizmet veren reklam ajansları, müşterilerinin talepleri doğrultusunda bu süreci etkin bir şekilde yönetmeye çalışmaktadırlar.

Reklam ajanslarının bu görselleştirme sürecinde karşılaştıkları problemlerin en başında renk kaynaklı problemler gelmektedir. Bu renk kaynaklı problemler reklam ajanları ve müşterileri arasında hukuki boyutlara kadar uzanabilen anlaşmazlıklar çıkarabilmektedir. Bu durum ise reklam ajanslarının prestij, müşteri, zaman ve bunlara bağlı maddi kayıplar yaşamalarına sebep olmaktadır. Bu sebeple reklam ajanslarının renklerle ilgili karşılaşacakları problemleri önceden bilmesi ve önlemler alması gerekmektedir. Fakat bu alanda yeterli kaynak olmaması sektördeki kurumların bilgiye sağlıklı şekilde ulaşmalarında en büyük engeli temsil etmektedir.

$\mathrm{Bu}$ çalışma ile bu sektöre hizmet veren kurumlara ve bu alanda eğitim veren kurumlara bir kaynak oluşturulması hedeflenmiştir. Bu hedef doğrultusunda yapılan çalışmada reklam ajanslarının basılı reklamların görselleştirilme aşamalarında renk evrenleri, baskı provası alımı, baskı altı malzemesi seçimi, baskı aşaması ve baskı sonrası süreçlerde karşılaşacakları renk problemleri ayrıntılı bir şekilde görsellerle ele alınmış ve nasıl çözecekleri konusunda da önerilerde bulunulmuştur.

Anahtar Kelimeler: Reklam Ajansı, Renk, CMYK, Görsel Tasarım

\section{ABSTRACT}

Printed advertising is one of the most important tools of communication industry. If it used effectively and correctly, it is possible to reach large audiences and convey the desired information in a healthy way. Advertising agencies serving the visualization process of ads

* ORCID: 0000-0002-8276-0024, Dr. Öğr. Üyesi，Marmara Üniversitesi，Uygulamalı Bilimler Yüksekokulu, Basım Teknolojileri Bölümü, batuhan@marmara.edu.tr 


\section{Reklam Ajanslarının Karşılaştığı Renk Kaynaklı Problemler Ve Çözüm Önerileri}

try to manage this process effectively in line with the demands of their customers. Colorrelated problems are at the top of the list of problems that advertising agencies encounter in this visualization process.

These color-related problems can cause disputes between advertising agents and their customers, which can extend to legal dimensions. This situation causes the advertising agencies to experience prestige, customer, time and financial losses related to these. For this reason, advertising agencies should be aware of the problems they will encounter with colors and take precautions. However, the lack of sufficient resources in this area represents the biggest obstacle for the institutions in the sector to access information in a healthy way.

With this study, it is aimed to create a resource for institutions serving this sector and institutions providing education in this field. In this study, the color problems that the advertising agencies will encounter in the visualization stages of the printed advertisements, printing proof, selection of printing substrate, printing stage and post-printing processes were discussed in detail with visuals and recommendations were made on how to solve them.

Key Words: Advertising Agency, Color, CMYK, Visual Design

\section{АННОТАЦИЯ}

Печатная реклама - один из важнейших инструментов индустрии коммуникаций. При эффективном и правильном использовании можно охватывать большую массу людей и передать желаемую информацию нужным образом. Рекламные агентства, обслуживающие процесс визуализации рекламы, стараются эффективно управлять этим процессом в соответствии с требованиями своих клиентов.

Проблемы, связанные с цветным оформлением, являются главной проблемой, с которыми сталкиваются рекламные агентства в процессе визуализации. Эти проблемы, могут привести к спорам между рекламными агентствами и их клиентами вплоть до правового разбирательства. Эта ситуация приводит к тому, что рекламные агентства несут связанные с этим потери сточки зрения престижа, клиентуры, времени и финансов. По этой причине рекламные агентства должны знать о проблемах, с которыми они могут столкнуться с цветным оформлением и принимать меры предосторожности. Однако, нехватка достаточных ресурсов в этой области представляет собой самое большое препятствие для учреждений сектора при доступе к информации в нормальных условиях.

Данное исследование направлено на создание ресурса для учреждений, обслуживающих этот сектор и учреждений, обеспечивающих образование в этой области. В исследовании, проведенном в соответствии с этой целью, были подробно обсуждены проблемы с цветным оформлением, с которыми рекламные агентства столкиваются на этапах визуализации печатной рекламы, при получении заказа и выборе дополнительных материалов для печати, на стадии печати и постпечатных процессах. Там же были внесены предложения по их решению.

Ключевые слова: рекламное агентство, цвет, СМҮК, визуальный дизайн.

\section{GIRISS}

Reklam ajansları müşterileri için, basılı ve elektronik medyayı kullanarak iletişim sorunlarına görsel çözümler planlarlar, analiz ederler ve bunlara görsel çözümler üretirler. Reklam ajansları gelen talepler doğrultusunda web sayfaları, etkileşimli medya ve multimedya projeleri dişında dergiler, gazeteler, kurumsal raporlar v.b. yayınların çeşitli türlerinin genel düzeni ile üretim tasarımını gerçekleştirirler. Bunlar dışında ambalaj ve pazarlama broşürleri üretir, ürünler ve 
işletmeler için logolar tasarlar, işyerleri için tabela ve tabela sistemleri geliştirirler. $\mathrm{Bu}$ görsel ürünlerin ortaya çıkma sürecinde temel elemanların biri renklerdir. Seçilmiş olan renklerin kullanılması ve bunların basılı hale geldikleri sürecin sonrasında bire bir aynı renklere ulaşabilmek en önemli amaçlarındandır (Becer, 2008).

Reklam ajanlarının müşteri ile karşılaştıkları problemlerin en başında ise renk kaynaklı problemler gelmektedir. Müşteri bask1 öncesi süreçte seçtiği ve ekranda gördügü rengi, iş bitiminde de görmek ister. Aksi durumlarda reklam ajanları, hem müşteri hem de maddi kayıplar yaşamaktadırlar.

Reklam ajanslarının yaşadıkları bu problemlerin büyük kısmı baskı öncesi hazırlık aşamasında gerçekleşen tasarımsal hatalardan kaynaklanmaktadır. Tasarımı gerçekleşen grafikerin sanatsal yeteneği çok güçlü olsa da renkler, renklerin elde edilişi ve sunuluşu konularındaki teknik yetersizlikleri bu problemlerin doğuşuna temel teşkil etmektedir. Bu problemlerin ortadan kaldırılması ise reklam ajanslarında bulunan çalışanların tasarım ve sonrasında rengin tanınması konularında gerekli hizmet içi eğitimler alması önemlidir.

Geçmişte tasarım halindeki bir iş hazırlanırken ekranda görünen rengi iş provasında, provadaki rengi ise iş basıldıktan sonra tam olarak yakalamak reklam ajansları için çok zordu. Günümüzde ise, teknolojik gelişmelerle birlikte bu problemler ortadan kaldırılabilmektedir. Reklam ajansları bu teknolojik değişimleri bünyesine katarak, renk kaynaklı problemlerin önüne geçebilmektedir.

Yapılan bu çalışmada reklam ajanslarının renk elde edilmesi süreçlerinde karşılaştıkları problemler ve bu problemleri çözmeye yönelik almaları gereken önlemlere yer verilmiştir.

\section{REKLAM AJANSLARININ KARŞILAŞTIĞI RENK KAYNAKLI PROBLEMLER}

\subsection{Renk Evreni Kaynaklı Problem}

Bask1 öncesinde kullanılan cihazlarda bask1 imajları elde edilirken kullanılan renk evreni ile baskıda imajların elde edilmesi sürecinde kullanılan mürekkeplerinin renk evrenleri birbirinden farklıdır. Basılacak imaj hazırlanırken 1şıksal renkler olan RGB renk evreni, basılırken de maddesel renk evreni olan CMYK renk evreni kullanılır. Dijital kameralar, tarayıcılar ve monitörler RGB renk evrenini, dijital çıkışlar, prova baskı makineleri ve baskı sistemleri CMYK renk evrenini kullanırlar (Mackay,2005). Sorun bu iki sistemi ortak bir dilde birleştirmek ve doğru rengi elde etmektir. Bu ise renk yönetim sistemi gerçekleştirilebilmektedir.

Renk yönetimi sistemleri, üretim aşamasında kullanılan cihazlar arasındaki renk dönüşümlerinin yapılmasını ve baskı sonucunun monitör ve provada simüle edilmesini sağlayarak bireylerin renkleri daha doğru algılamalarına yardımcı olan bir sistemdir. Bu işlemin başarabilmesi sistem içinde kullanılan cihaz ve makinelerin görebildiği ya da üretebildiği renk evreninin sınırlarının bilinmesi gerekmektedir (Köse ve Şahinbaşkan, 2008). 


\section{Reklam Ajanslarının Karşılaştığı Renk Kaynaklı Problemler Ve Çözüm Önerileri}

Baskı öncesi çalışanlarının, tasarım sürecinde renk ölçüm cihazlarında hangi ayarları kullandıklarını belirtmeleri son derece önemlidir. Çünkü doğru renk üretimi her cihaz için çalışma alanı ve renk ayarları operatör tarafından kullanılan orijinal ayarlara uyacak şekilde ayarlandığında elde edilebilir (Abildgaard, 2016). Örneğin RGB çalışma alanlarını seçerken, Adobe Creative Suite içindeki Adobe RGB ve sRGB arasında belirgin bir fark vardır. Adobe RGB, 1.2 milyon renk gamı hacmine ve sRGB, $\sqrt{3}$ renk farkı toleransı dahilinde yeniden üretilebilecek renk sayısını temsil eden 830 bin renk gamı hacmine sahiptir; bu nedenle, Adobe RGB'nin seçilmesi daha geniş bir renk yelpazesi sağlayacaktır (Chovancova-Lovell ve Fleming 2009). RGB çalışma alanlarının yanı sıra, operatörler belgelerindeki renk ayarlarını CMYK, RGB, HEX veya Pantone değerleri olarak belirleme yeteneğine sahiptir. Dijital

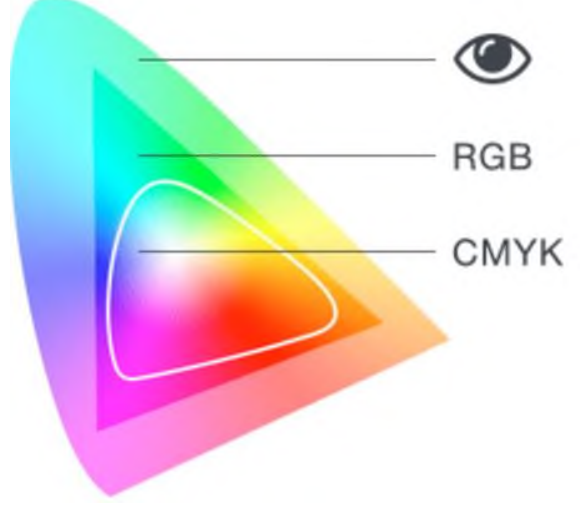

ortamda baskı yaparken veya yayınlarken her seçim farklı sonuçlar üretecektir. Bir iş akış1 içinde doğru renk yönetimini kullanmak kadar, hangi çalışma alanının kullanıldığı ve bu çalışma alanı için hangi renk ayarlarının kullanıldığı her zaman belirtilmelidir.

Şekil 1. Gözün algıladığı, görüntüleme cihazlarının (RGB) ve baskı makinelerinin (CMYK) görülebilen renk evreni (URL1)

Reklam ajanslarında işler CMYK renk evreninde işler hazırlanmış olsa da monitörlerde renkler 1şıksal renkler olan RGB renk evrenleri dahilinde görülmektedir. Eğer tasarımcı herhangi CMYK kataloğu kullanmadan gerekli renk değerlerini düzenlemiş ya da direkt RGB renkler ile tasarımı gerçekleştirip, müşteriden onay almışsa, baskı sonrasında istemediği renk değerleri ile karşılaşması olas1 bir durumdur. Çünkü matbaalarda da işler bask1 altı malzemesi üzerine mürekkepler ile aktarılmaktadır. Mürekkeplerden renk elde edilmesi ise maddesel renkler olan CMYK renk evrenine dayanır (Guryanova et all, 2020). CMYK renk evreni RGB renk evreni daha dar (Şekil 1) olduğundan, çoğu rengin elde edilmesi imkansızdır (Şekil 2). 


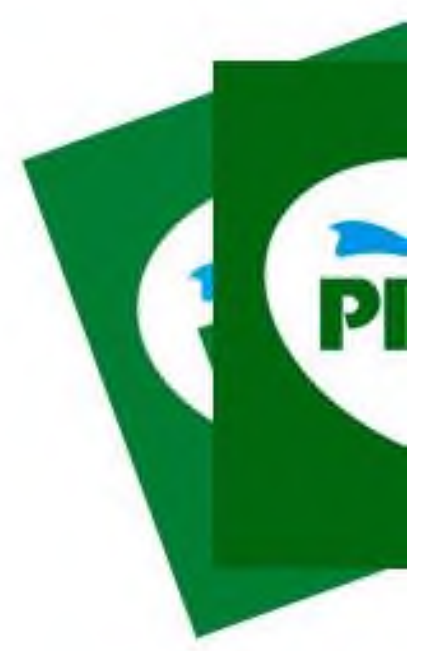

Şekil 2. CMYK dönüşümü yapılmamış ve yapılmış baskıdaki renk farklılı̆̆1

Reklam ajanslarının bu renk problemi ile karşılaşmaması için tasarımları gerçekleştirirken renk belirleme aşamasında CMYK renk evrenini kullanmaları, RGB renk evreni ile çalışılmış ise de mutlaka prova alırken veya işi matbaaya yollarken, üzerinde çalıştıkları işleri CMYK renk evrenine dönüştürmeleri ve gerekli renk düzenlemelerini yapmaları gerekmektedir. Aksi halde basılan renkler tasarım aşamasındaki renklerle uyuşmayacağından ortaya bambaşka renkler çıkacaktır.

Tasarım sürecindeki renklendirme ile ilgili bir diğer problem ise ekstra (spot) renklerin bilinçsizce kullanılmasından kaynaklanmaktadır. Spot renk, CMYK baskısı ile elde edilmesi mümkün olmayan bir rengin elde edilmesi veya kurumsal bir rengi elde etmek için kullanılmaktadır. Bu süreçte iki farklı durum ile karşılaşılabilmektedir. İlki Şekil 3 de görülen herhangi bir renk kataloğu (pantone kataloğu) kullanılmadan spot rengin belirlenmesi, diğer durum ise spot rengin bilinçsizce kullanılmasıdır. Renkler konusunda yetersiz bilgiye sahip olunması durumunda tasarımın tümünün spot renklerden oluşturulması ile karşı karşıya kalınabilir. Spot renklerin belirlenmesi aşamasında kağıdın kuşelenmiş ya da kuşelenmemiş olmasına bağlı olarak ilgili pantone kataloğundan renk seçimi gerçekleştirilmelidir. Yapılmazsa, spot renkli hazırlanan iş baskıya gönderilken CMYK'ya dönüştürülecek ve CMYK mürekkepler ile basıldığında da bariz renk farkl11ıkları ortaya çıkacaktır (Şekil 2). Bu sebeple grafikerin mutlaka işi baskıya göndermeden önce gerekli renk evreni dönüşümü yapıp, prova alması ve onay sürecinden sonra baskıya göndermesi gerekmektedir. 


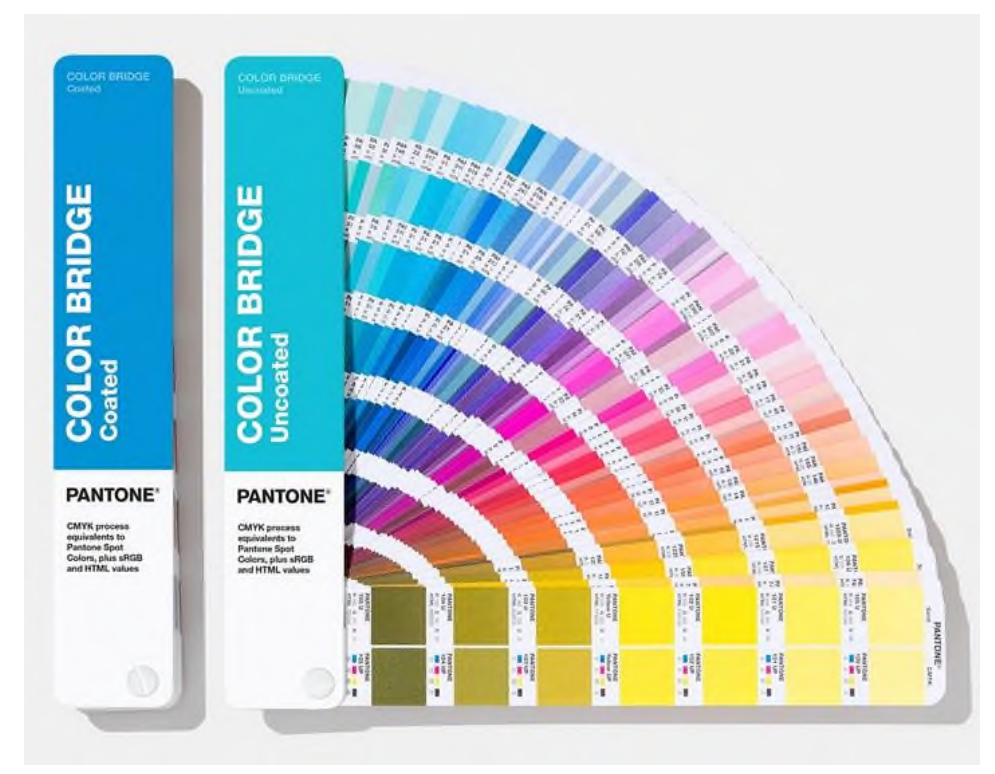

Şekil 3. Pantone kataloğu (URL2)

\section{Renk Provası Kaynaklı Problemler}

Dijital provalarda linerizasyon işlemi yapılır. Linerizasyon, kısaca dijital provanın kullanılan kâğıda göre mürekkep verme miktarının belirlenmesidir. Linerizasyonu yapılmamış bir dijital prova sistemi, renkleri doğru oluşturmak için gerekli olan mürekkep miktarlarını bilemeyeceğinden, ya çok miktarda ya da az miktarda mürekkep kullanarak doğru sonuca ulaşılması imkansız hale gelecektir (Mutafoğlu, 2009). 
Renk yönetimindeki en büyük sorun baskıdaki renk kalibrasyonunu oluşturmaktır. Basılacak iş hazırlanırken kullanılan cihazların renk kalibrasyonun çok iyi yapılması baskı kalibrasyonunu etkilemez. Bu nedenle baskı öncesi ile baskı kalibrasyonlarının anlaşabilmesi için bir profil oluşturulması gereklidir. Profil oluşturma, basılacak ürünün tasarımından baskısına kadar kullanılan her makine ve cihazın renk evreninin oluşturulmasıdır. Bu işleme cihazın parmak izinin çıkarılması adı verilir. Her cihazın (Şekil 4) renk evreninin oluşturulmasıyla her bir cihaz eşleştirilerek birbirini simüle etmesi sağlanır. Bu profillerin adına International

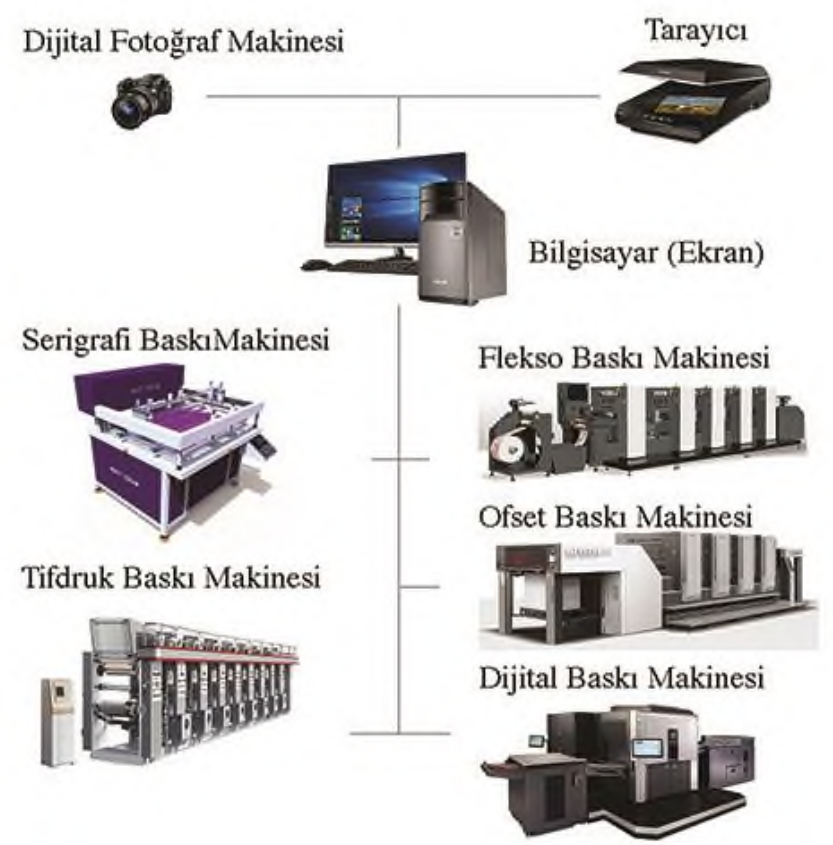

Colour Consortium Profili (ICC Profili) adı verilir. Bu profiller kullanılan renk yönetim sistemi programlarına tanıtılarak her cihazın birbiri ile tanışması sağlanır. $\mathrm{Bu}$ profiller oluşturulurken kolorimetrik ölçüm cihazları kullanılır.

Şekil 4. Baskı öncesi hazırlık cihazları ve baskı makineleri

Reklam ajanslarının baskı sonucunda istenen renklerin olduğu prova baskıyı almadan, profili oluşturulmamış yazıcı çıktısıyla sipariş verdiklerinde baskı operatörleri profilsiz baskıya göre üretime girerler (Şekil 5). Bunun sonucunda iş bitiminde çıan renkler ile istenen renkler birbiri ile uyuşmaz. $\mathrm{Bu}$ da basılı tüm ürünün istenilen renk değerlerinde elde edilememesine neden olur. Bu durum reklam ajanslarının hem emek hem de maddi kayıplar yaşamalarına sebebiyet verir. 
a

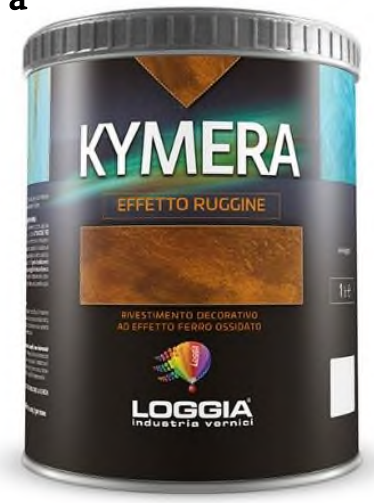

b

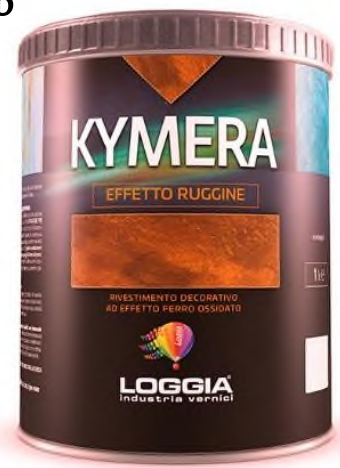

Şekil 5. Renk provası alınarak basılan iş (a) ve renk provası alınmadan basılan iş (b) örnekleri

\section{Baskı altı Malzemesi Kaynaklı Problemler}

Reklam ajansları basılacak olan işin niteliğini tam olarak belirleyip tasarımları ona göre gerçekleştirmelidir. Çünkü baskı altı malzemeleri ve sahip oldukları optik ve fiziksel özellikler birbirinden çok farklıdır. Bu farklılıkların en başında baskı altı malzemesinin beyazlığı, parlaklığı ve rengi gelmektedir ki bunlar baskı sonrası elde edilecek rengi etkileyen temel unsurlardır. Reklam ajanslarının bask1 altı malzemesinin temel özelliklerini düşünmeden renk seçimi yaparak tasarımda bunları kullanması durumunda, bask1 sonrasında istenmeyen renk değerleri ile karşılaşılması mümkündür. Bunun önüne geçmek için mutlaka üretimde kullanılacak baskı altı malzemesi düşünülerek renk seçimleri gerçekleştirilmeli ve tasarım sonrasında baskı provası alınması aşamasında da üretimde kullanılan baskı altı malzemesinin aynı baskı altı malzemesi ile prova alınması gerekmektedir (Şekil $6)$.

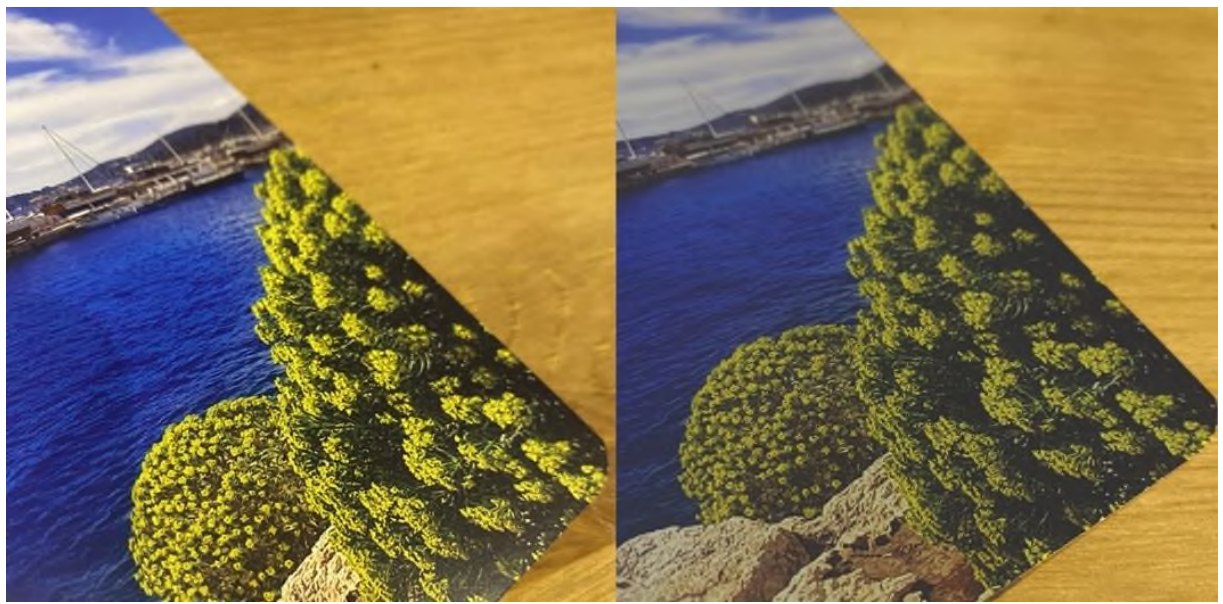

Şekil 6. Farklı optik ve fiziksel özelliğe sahip kağıtlardaki renk farklılığı 


\section{Trapping Kaynaklı Renk Problemi}

Dijital Trapping, üst üste farklı renklerde basılan işlerde en çok karşılaşılan grafik tasarım problemlerindendir. Trapping kelimesi tasarım aşamasında kullanılan bir kelime olmakla birlikte, baskı aşamasında ilk basılan rengin ikinci basılan rengi kabul etme yüzdesini belirtmekte de kullanılan bir terimdir (Sönmez, 2011). Bu iki sorunun grafik kısmında olan kısmına dijital trapping denir. Bask1 sistemlerine yapılan hazırlık aşamasında eğer taşma payı fazla verilirse basılan görüntüyü çevreleyen farklı bir renkte kontür oluşmasına, verilmediği durumlarda ise baskıda çok az miktarda bir kayma olduğunda, imajın kenarlarında baskı altı malzemesinin renginin gözükmesine neden olacaktır (Uçar, 2004) (Şekil 4). Aynı şekilde birbiri üstüne binen zemin alanlarının ya da zemin alanı üzerindeki yazı karakterlerinin altları boşaltılmaması (overprint uygulaması) yapılmaması durumunda da istenmeyen renk değerleri ile karşılaşılmaktadır.

a

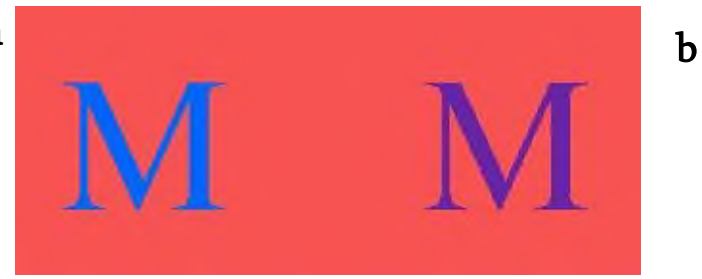

Şekil 7. Overprint ayarı yapılmış (a), overprint ayarı yapılmamış (b)

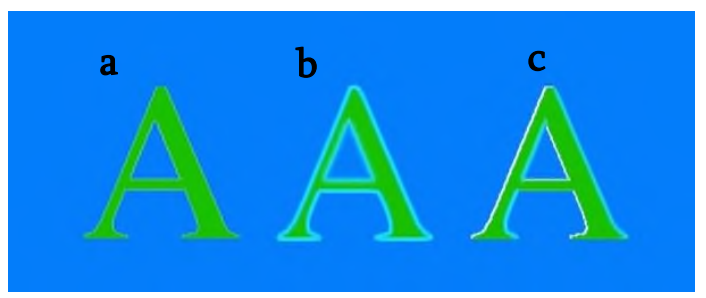

Şekil 8. Taşma payı olması gereken (a), fazla verilmiş (b), taşma payı az verilmiş (c)

\section{Üretim Süreci Kaynaklı Renk Problemleri}

Üretim süreci bask1 süreci ve bask1 sonrası süreç olarak iki basamakta gerçekleşmektedir. $\mathrm{Bu}$ süreçlerde yaşanan renk problemler ayrı başlıklar altında aşağıda incelenmiştir. Bunlar:

\section{a) Baskı Süreci}

Baskı sürecinde oluşan problemlerin başında mürekkep seçimi gelir. Process renkler (Trikromik renkler) olarak adlandırılan C (Cyan), M (Magenta), Y (Yellow) ve K (Key) olarak dört renkten oluşur. Bunların dışında harici kullanılan spot renkler 


\section{Reklam Ajanslarının Karşılaştığı Renk Kaynaklı Problemler Ve Çözüm Önerileri}

bulunmaktadir.

Process renkler baskı sektöründe farklı markalar tarafinan üretilmektedir. Hatta aynı markanın process renkleri farklı seri renklerde de bulunmaktadır. Doğal olarak markalar aynı olsada farklı seriler farklı renk değerlerine sahip olabilmektedir. Bu sebeple baskı sürecine hangi seri mürekkep ile başlanılmışsa iş bitene kadar aynı seri mürekkep ile devam edilmesi renk farkl1lıklarının önüne geçilmesi bakımından önemlidir. Bu süreçte reklam ajanslarının çalıştığı matbaanın baskı şartları bilmesi ve yakından takip etmesi önemlidir (Polat, 2014). Tasarımda kullanacağı renkleri de bu teknik bilgiler doğrultusunda yapmalı ve baskı sürecini yakından takip etmelidir.

\section{b) Baskı Sonrası Süreci}

Reklam ajansları yaptıkları çalışmaları hem farklı görsellik katmak hem de dış etkenlere karşı dayanımı arttırmak amacıyla selefon ya da lak gibi baskı sonrası işlemlerden yararlanabilmektedir.

Basılmış bir renk üzerine selofan malzemesinin lamine edilmesi sürecinde yapıştırma amacı ile kullanılan tutkal, bu tutkalın miktarı ve selofanın şeffaflığı baskı rengine direkt olarak etki eder. Baskıda elde edilmiş soluk bir renk daha canlı, canlı olan renk ise daha soluk ya da farklı renk tonlarında elde edilmesi ile karşılaşılabilinir (Şekil 9).
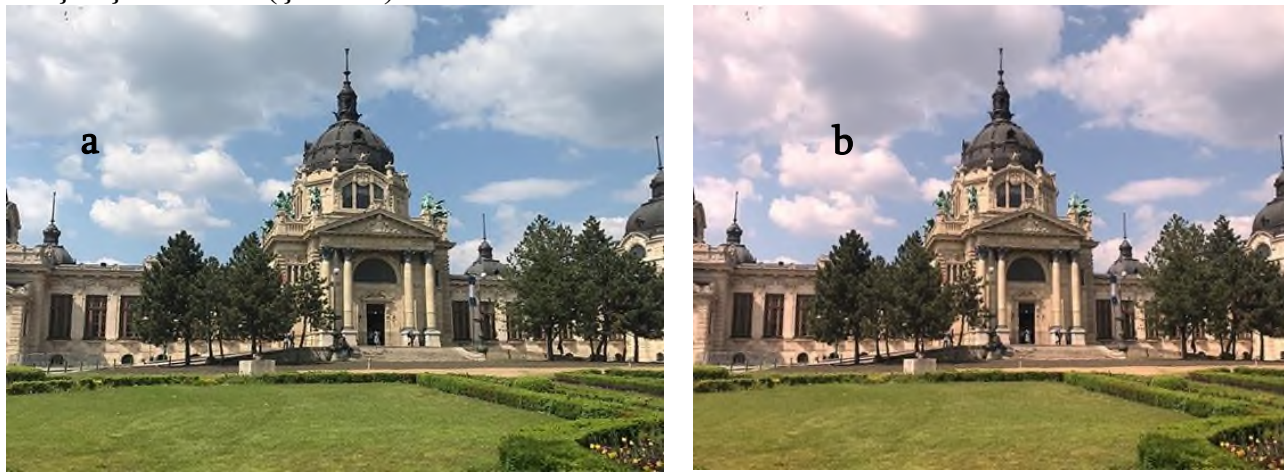

Şekil 9. Selofan uygulaması yapılmamış (a), Selofan uygulaması yapılmamış (b)

Yine aynı şekilde reklam ajanslarının tasarımlarda bazı alanların daha canlı göstermek amacı ile lak uygulamasını tercih edebilir. Bu durumda ise lakın kimyasal özelliği, parlak ya da mat olması istenilen renklerin farklı görünmesine neden olacaktır.

$\mathrm{Bu}$ sebeplerden dolayı reklam ajansları tarafindan tasarımlarında bu işlemler tercih edilecekse renklerdeki değişimler önceden düşünülmeli ve gerekli önlemleri alınmalıdır.

\section{SONUÇLAR VE ÖNERÍLER}

Yaşanılan bu problemlerin önüne geçmek için ilk ve en önemli adım reklam ajansı çalışanlarının renk ve baskı konusunda eğitim almaları gerekmektedir.

Ajansta kullanılan dijital fotoğraf makinesinin, tarayıcıların ve kullanılan 
monitörlerin, matbaa tarafinda ise baskıda kullanılacak olan tüm makinelerin ICC profillerinin (parmak izinin) mutlaka çıkarılması gereklidir. Böylelikle reklam ajansında kullanılan bilgisayarın monitöründe görülen renk ile baskı sonucunda çıkan renkler birbiri ile aynı olacaktır.

Tasarımcı işe başlarken CMYK renk evrenini kullanması gerekmektedir. RGB renk evreninde çalışılmış ise iş baskıya gönderilmeden önce mutlaka işi CMYK dönüşümünü mutlaka yapılmalı ve dönüşüm sürecinde renklerde meydana gelmiş değişimler düzeltilmelidir.

Tasarımlarda renklerin elde edilmesi ve tercihlere bağlı olarak trikromi renkler ya da spot renkler tercih edilebilir. Fakat bu süreçte her bir baskı renginin reklam ajanslarına ekstra bir maliyet getireceği göz önünde bulundurulmalıdır.

Baskıya geçmeden önce prova baskının alınması, baskı provasının üretimde kullanılan baskı altı malzemesi ile aynı olması sağlanmalıdır.

Tasarım aşamasında trapping ve overprint ayarlarına dikkat edilerek, hem bu süreçten kaynaklı renk problemleri hem de baskı aşamasında makina ayarlarından kaynaklanan problemler önlenebilir.

İşin baskı sürecinde hangi marka mürekkep ile başlandıysa, aynı marka mürekkep ile devam edilmesi baskı renklerindeki devamlılı̆̆ın sağlanması bakımından önemlidir.

Basılmış renkler üzerinde selofan ve lak uygulaması gerçekleşecekse, elde edilecek renk değerlerinde olabilecek değişimler göz önünde tutularak gerekli renk düzeltmeleri yapılmalıdır.

\section{KAYNAKÇA}

Abildgaard, M. (2016). Why most Brand Manuals fail when it comes to defining

Brand Colors; And how to determine acceptable color deviations for specific Brand Colors. Proceedings of 42nd International Research Conference, Ryerson University, USA.

Becer, E., (2008). İletişim ve Grafik Tasarım. (6. Basım). Ankara: Dost Kitabevi Yayinlar1.

Chovancova-Lovell, V., \& Fleming III, P. D. (2009). Color Gamut - New Tool in the Pressroom, TAPPI J, 4-11.

Guryanova, O, Gnibeda, A. , Filimonova, E., Pukhova, E., Kotelnitskaya, L., "The Application of Information Technologies for Color Reproduction and Technical System Management in Printing Art Production", (2020), E3S Web of Conferences 210, https://doi.org/10.1051/e3sconf/202021002001.

Köse, E. ve Şahinbaşkan, T. (2008)," Renk yönetiminde kullanılan standart ICC profillerinin Türkiye' de oluşturulmuş bazı profiller ile karşılaştırılması", Politeknik Dergisi, 11(4), 365-371.

Mackay, A., "The Practice of Advertising Fifth Edition", Elsevier Publishing, 2005, s 141.

Mutafoğlu, İ. C. (2013). Matbaalar ve Reklam Ajansları Arasındaki Teknik

\section{Problemlerin}


Tespiti Ve Çözüm Önerileri, Marmara Üniversitesi Fen Bilimleri Enstitüsü, Yüksek Lisans Tezi, İstanbul,

Polat, A.A., (2014). "Tasarımcıların Dijital Ortamda Veri Gönderme ve Arşivleme Yöntemleri", E-Journal of New World Sciences Academy, Volume 9 , Issue 2, Pages 46 - 54.

Sönmez, S., (2011). Tasarım Kaynaklı Baskı Problemlerinin Çözümünde Grafik Tasarım Eğitiminin Önemi, Marmara Üniversitesi Fen Bilimleri Dergisi, 23(1): 1-11.

Uçar, T.F., (2004). Görsel İletişim ve Grafik Tasarım. İstanbul: İnkılap Kitabevi.

INTERNET KAYNAKÇASI

URL 1: https://www.kwikkopylufkin.com/rgb-cmyk-whats-the-difference/ (19.01.2021)

URL 2: https://www.pantone.com/color-bridge-guide-set-coated-uncoated, (19.01.2021) 